\title{
A FORMAÇÃO DO TERRITÓRIO BRASILEIRO EM PERSPECTIVA: MODERNIZAÇÃO, DESENVOLVIMENTISMO E APROPRIAÇÃO CORPORATIVA DO ESPAÇO
}

\author{
Ulysses da Cunha Baggio ${ }^{1}$
}

\begin{abstract}
Resumo: $O$ artigo busca analisar aspectos marcantes da formação do território brasileiro, conferindo maior ênfase às ações e políticas do Estado neste processo, sobretudo sob a chamada modernização conservadora e o desenvolvimentismo. A análise pretendeu apreender a historicidade desse processo, recobrindo o período colonial até os dias atuais. Procurou-se por em relevo a forma contraditória que marcou tal processo, com centralização do poder político, dispersão-fragmentação socioespacial e formação de estruturas concentracionistas e desiguais, especialmente a partir do período JK (1956-1960), sob uma maior articulação entre o Estado e frações hegemônicas do capital nacional e internacional. Consideram-se seus desdobramentos e conformações socioespaciais mais atuais, compreendendo usos e apropriações corporativos do território, num contexto de desenvolvimento de uma urbanização extensiva e de crise/financeirização da economia.
\end{abstract}

Palavras-chave: Formação territorial; Estado; modernização conservadora; desenvolvimentismo; apropriação corporativa do espaço.

\section{THE FORMATION OF THE BRAZILIAN TERRITORY IN PERSPECTIVE: MODERNIZATION, DEVELOPMENTALISM AND CORPORATE APPROPRIATION OF SPACE}

\begin{abstract}
The article seeks to analyze outstanding aspects of the formation of the brazilian territory, giving greater emphasis to the actions and policies of the State in this process, especially under the so - called conservative modernization and developmentalism. The analysis sought to apprehend the historicity of this process, overlaying the colonial period to the preset day. Sought to highlight the contradictory form that marked this process, with centralisation of political power, dispersionfragmentation Socio-spatial and formation of structures concentracionistas and unequal, especially from the JK (1956-1960), under a greater articulation between the State and hegemonic fractions of national and international capital. They are considered their most current socio-spatial developments and conformations, comprising corporate uses and appropriation of the territory, in the context of the development of extensive urbanization and crisis/ financialization of the economy.
\end{abstract}

\footnotetext{
${ }^{1}$ Prof. Dr. da Universidade Federal de Viçosa - Departamento de Geografia. ulybaggio@ufv.br
} 
Keywords: Territorial formation; State; Conservative modernization; Developmentalism; Corporate appropriation of space

\section{INTRODUÇÃO E PERSPECTIVA METODOLÓGICA}

O presente artigo busca explorar aspectos considerados relevantes na formação do território brasileiro, recobrindo desde o período colonial até os dias atuais, dando maior ênfase à fase de realização da modernização conservadora deflagrada por Getúlio Vargas a partir dos anos 1930 e o desenvolvimentismo, com seus desdobramentos socioespaciais. Sob os efeitos de uma urbanização extensiva, geograficamente dispersa, intervêm os influxos da crise contemporânea e, de modo relacionado, da financeirização da economia, destacando-se implicações quanto a apropriações territoriais de caráter privado-corporativo, em curso. Desse modo, intentamos apreender não apenas expressões socioespaciais consideradas importantes nesse processo, e merecedoras de registro, mas também o seu sentido, que comporta uma dimensão política.

Desse modo, a formação do território brasileiro se coloca em perspectiva têmporo-espacial, cuja dinâmica evolutiva revela-nos grafias e traços que reverberam até os dias atuais. Por tal perspectiva buscamos iluminar a interação diacronicamente dialética entre sociedade e natureza, da qual resulta a formação de quaisquer territórios.

Compreende-se que a formação de um dado território implica, invariavelmente, em apropriação material e simbólica do espaço, em escalas e circunstâncias diversas, sendo-Ihe imprescindíveis ações políticas ao seu controle e dominação. Daí o território revelar-se como uma inscrição socioespacial essencialmente política, logo um campo de poder, de disputas e conflitos.

Ontologicamente, a formação territorial pressupõe um processo cumulativo e desigual de temporalidades, articulando práticas econômicas, políticas e culturais, que lhe imprimem atributos materiais e simbólicos, continuamente produzidos, destruídos, transformados, (re)apropriados e (re)funcionalizados.

Embora nas sociedades modernas a ação estatal constitua uma variável geopolítica fundamental na formação dos estados nacionais, é forçoso salientar que a formação territorial também recobre, sobretudo em países da periferia do sistemamundo, práticas sociais cotidianas demarcadas por relações cooperativas de ajudamútua. Estas são dotadas de certo caráter auto-organizacional e mobilizam atores sociais que operam de "baixo para cima", num circuito paralelo ao do Estado, como atesta, notadamente, a produção permanente de parte expressiva de nossas periferias urbanas.

Nas sociedades contemporâneas, bastante submetidas à globalização e a processos de reestruturação territorial, a imagem que melhor se aproximaria de suas conformações socioespaciais é a de um mosaico de fractais, a exemplo de conglomerados metropolitanos. Na América Latina e no Brasil eles se expandem celeremente, junto ao crescimento tendencial de cidades médias, atualizando, de certo modo, o desenvolvimento desigual através de reconcentrações econômicas e populacionais. Nesse contexto, a crise das economias de aglomeração em moldes fordistas e movimentos correspondentes de desconcentração territorial do capital industrial estão na base da formação desses campos aglomerativos urbanos, que 
alcançam proporções regionais, como o representado pela "megarregião" São Paulo - Rio de Janeiro (LENCIONI, 2015).

A reestruturação territorial vem estabelecendo a constituição de novas centralidades espaço-regionais, dotadas de uma maior densidade de sistemas de relações, que potencializam os fluxos de mercadorias, capitais, informação e força de trabalho, podendo-se destacar a conformação preeminente verificada no interior do que corresponde, "grosso modo", ao centro-sul do país. À medida que estes espaços demandem estratégias políticas cooperativas à sua ordenação e governança, o problema representado pela administração das diferenças e da mitigação das desigualdades torna-se politicamente central.

Se o mundo atual torna-se, crescentemente, o palco de mobilidades populacionais cruzadas, no qual as turbulências socioespaciais e os estranhamentos entre as diferenças e os diferentes tendem a aumentar, ele, ao mesmo tempo, nos dá a ampliação da sócio-diversidade dos lugares, tornando-os tanto mais disputados como enriquecidos social e culturalmente. O que abre novas possibilidades à experiência humana e geográfica cotidianas, em face de dificuldades e compressões constantes.

Assim, à medida que o território esteja pautado na apropriação e no uso social dos lugares, ele reflete a diversidade de relações sociais e cotidianas, onde também se incluem as intersubjetivas relacionadas a demandas e necessidades de produção (trabalho) e de viver. Isso o torna meio, condição e processo dessas relações, recobrindo dinâmicas e conformações espaciais em múltiplas escalas (SAQUET, 2010). Um dos seus atributos mais importantes é a sua estreita associação com a (vida) política.

Da apropriação histórica da natureza, por meio do trabalho social, decorre o duplo movimento de sua socialização e incorporação desigual de valor. É neste sentido que o trabalho (ação criativa entre os homens na natureza) comparece como uma mediação universal na relação entre sociedade e natureza, em quaisquer tempos e lugares na história. Nesta relação se realiza a "valorização do espaço", recobrindo aspectos diversos do labor humano, não se restringindo tão somente aos limites estritamente econômicos, mas compreendendo também processos ecológicos, culturais, políticos, simbólicos e cognitivos (MORAES; COSTA, 1987).

Desse modo, as formas produzidas pelo trabalho retêm, desde a origem, funcionalidades e intencionalidades do processo social, que se transformam sob as demandas das sociedades em movimento. Tal movimento é essencialmente diacrônico e contraditório. Uma vez que os processos sociais pressuponham a produção e a reprodução permanentes do espaço, o próprio transcurso da vida humana representa um processo permanente de sua produção e reprodução, bem como da paisagem e da cultura (SANTOS, 1988).

Uma vez que as formas territoriais, em suas múltiplas escalas, recobrem articulações e entrelaçamentos desiguais, em que cada forma retém um emprego do tempo, o território e o tempo constituem uma totalidade social, formando uma unidade indissociável.

O Estado, como se sabe, tornou-se um ator central na formação territorial das sociedades modernas. Em países periféricos de industrialização tardia, como é o caso, emblemático, do Brasil, a atuação estatal deu-se de forma ainda mais contundente e, neste caso, com uma atuação marcadamente centralizada e autoritária. Tais aspectos estarão respondendo pela imposição de uma efetiva territorialidade estatal no país (MORAES, 2005), conferindo ao território expressiva hierarquização e seletividade. 
A partir da segunda metade do século $X X$, tal territorialidade se consolidou, expondo ações protagonizadas por grandes empresas e corporações, contanto com grande suporte do Estado. Assim, afirmou-se um robusto poder padronizador e disciplinador no território, que então se reconfigura, a passos rápidos, pela instauração de grandes projetos mínero-metalúrgicos, energéticos, petroquímicos e agro-industriais. Isso fez precipitar movimentos de resistência e lutas outras em decorrência de impactos socioespaciais e ambientais indesejados.

No âmbito dessa relação orgânica entre Estado e capital, o território (e os negócios em torno dele) se torna um suporte fundamental às demandas de valorização do capital, multiplicando os circuitos à sua espetacular monopolização à escala global. No Brasil, e a partir dele, este movimento se estende a outros espaços nacionais, sobretudo na América do Sul, por força de suas transnacionais.

Nesse sentido, pode-se compreender que o território tenha se tornado crucial à própria sustentação e sobrevivência do sistema capitalista, proporcionando-lhe condições reprodutivas que lhe conferem maior duração e extensividade, como o revela, por exemplo, as estratégias de alocação geográfica de capitais desvalorizados em contextos de crise. Em seu ciclo atual, este mecanismo de transferência tem vindo acompanhado por crescentes práticas espoliativas (HARVEY, 2004), sinalizando impasses e grandes restrições à própria acumulação. Sob esta condição avança uma impressionante concentração da riqueza mundial e a exacerbação da desigualdade (PIKETTY, 2014), amoldando espacialidades assimétricas e conflituosas, na qual empresas-corporações ostentam faturamentos superiores a PIBs de países inteiros.

No Brasil, o desenvolvimento e o dinamismo alcançado por estas empresas continuam contando com um decidido suporte do Estado, operando na reorganização destes poderosos grupos econômicos, sob o intuito pretensamente estratégico de propiciar a inserção competitiva destas empresas no mercado e do próprio país na nova ordem econômica planetária. Segue-se daí uma dinâmica altamente concentracionista do capital, que em nada se confunde com uma espécie de apoio à gestão empresarial, tratando-se mais propriamente de um "Estado convertido em ator de fusões e megaoperações e, portanto, em sócio ativo da maioria das empresas do país" (ZIBECHI, 2012, p.160).

\section{UM PANORAMA SUCINTO DA FORMAÇÃO DO TERRITÓRIO BRASILEIRO ATÉ OS ANOS 1930}

A gênese do Estado-nação brasileiro se dá no curso da expansão mercantilcolonial européia do século XVI. A ação colonizadora portuguesa e o estabelecimento de bases locais na colônia demarcam a origem da formação do território colonial.

Dispersão e descontinuidade foram aspectos marcantes da ocupação do território colonial, que integram a geopolítica da Coroa portuguesa na colônia. Tal cenário expunha a segmentação de uma diversidade de regiões ou enclaves vinculados à economia metropolitana ou de países industrializados, tais como a Inglaterra, configurando um modo de economia mercantilista baseada em uma forma de acumulação primitiva do capital. Embora estas regiões revelassem significativa desarticulação interna, este traço não se apresentava, no entanto, de forma total ou absoluta, como ilhas isoladas ou arquipélagos (como geralmente se diz). $E$ isso em função da existência de uma pecuária além Rio São Francisco, cujo movimento 
ascensional se fazia avançar pelo hinterland do território, ao lado de fluxos espaciais do comércio de escravos. Estes aspectos respondiam por certos entrelaçamentos entre regiões econômicas da colônia e regiões individuais, parcial e complementarmente estruturadas (NOVY, 2002, p.99).

Esse cenário era permeado por articulações imperfeitas ou incompletas, tributários do caráter extrovertido da economia colonial. O núcleo dinâmico dessa economia era dado pelo setor de mercado externo (SINGER, 1968), com as atividades comerciais e de povoamento sob o comando e os interesses dos grupos econômicos atrelados à exportação. A orientação econômica extrovertida foi um aspecto crucial à transformação das localidades de portos marítimos em centros econômicos de artigos coloniais (SINGER, 1968, p.199). A regulação dos processos econômicos era, pois, conduzida por instituições centrais submetidas ao estatuto colonial (NOVY, 2002, p.94).

O setor de mercado externo demandava um conjunto de atividades produtivas internas à colônia, voltadas à subsistência e ao abastecimento, como o fornecimento de alimentos (gêneros agrícolas, carnes salgadas), animais de tração e transporte (muares do sul da colônia, por exemplo), entre outros. Estas atividades operavam como vetores adicionais de ocupação e formação do território colonial.

Envolvendo grandes distâncias e extensos "vazios" entre os espaços de povoamento, a dispersão e a desintegração obstaram, praticamente, uma maior integração do território, o que contribuiu substancialmente para atrasar a formação do mercado colonial, impondo restrições à própria industrialização/modernização.

Com a consolidação da emancipação política do Brasil (parte da estratégia britânica ao controle da América do Sul por meio do livre comércio), as elites brasileiras deram início à instalação de um novo Estado, cuja criação se antecipa à formação da nação. Com um amplo território dotado de extensões ainda não ocupadas e uma população numericamente pouco expressiva e bastante cindida pela vigência da escravidão, a constituição da nacionalidade era restringida, ao mesmo tempo em que se estimulava uma concepção de país identificada mais com o território do que com a sociedade. (MORAES, 2005)

Esta concepção derivava do pacto oligárquico firmado entre as elites regionais, bases da sustentação política do novo Estado, Este se orientava pela idéia de se "construir o país", sob o sentido de um projeto nacional, que nortearia a integração de seu território. Atravessando diferentes conjunturas e distintos atores políticos, esta idéia se estabeleceu como "uma das metas hegemônicas na história do império brasileiro" (MORAES, 2005, p.93), operando como uma força de coesão entre as elites. Mostrando-se como uma concepção estritamente instrumental em relação ao povo, que era encarado mais como um meio e não como um objetivo, tal empreitada assume o sentido de uma missão civilizatória, conduzindo a "civilização" aos sertões e rendendo a "barbárie". Daí uma visão de natureza e do meio natural associada à idéia de barbárie e arcaísmo, relacionando, do mesmo modo, ocupação e devastação à idéia de progresso. Repousam aqui as raízes históricas do "padrão dilapidador" geograficamente extensivo e intensivo do processo de ocupação e apropriação do território brasileiro (MORAES, 1997; MORAES, 2005), que reverbera, aliás, até os dias atuais. O caso do povoamento e da exploração da grande fronteira amazônica a partir dos anos 1970, sobretudo, é emblemático nesse sentido.

Já na segunda metade do século XIX era perceptível certa consolidação do Estado como instituição, favorecendo condições à política nacional, que adquiria maior importância. Isso, não necessariamente, esclareça-se, representou uma espécie de renúncia ao consenso liberal propagado pela Grã-Bretanha, mais 
especificamente no que concerne à sua grande projeção no livre-comércio. Contudo, já em fins do século XIX ela já vinha perdendo força ideológica em relação a isso. No Brasil, durante a República Velha (1889-1930), já se podiam observar a adoção de posturas mais pragmáticas, conducentes a melhorias em algumas regiões em termos de infra-estruturas ao setor produtivo, visando sua maior competitividade.

No curso desses acontecimentos, o Brasil pouco a pouco foi se transformando de uma sociedade marcadamente rural para uma tendencialmente urbana. Banqueiros e atravessadores ganhavam importância em relação aos latifundiários, levando ao deslocamento da primazia da esfera da produção em benefício da esfera da circulação. As ações modernizantes iam fragilizando a preservação de velhos poderes políticos sobre o território. Considere-se aqui o fim da escravatura e da monarquia, compelindo os donos de escravos a se transformarem em latifundiários e exportadores de bens primários, sob o risco de ficarem à margem da nova estrutura de poder.

O Estado servia, então, tanto aos interesses da oligarquia agrária conservadora, que então dominava, quanto aos interesses do setor comercial urbano. Ele já se apresentava em 1930 bem mais forte do que se costuma afirmar, tendo se transformado, na República Velha, "em instância reguladora da economia e produtor de partes substanciais de infra-estrutura econômica", o que solicitava uma progressiva e necessária introdução do trabalho livre assalariado (NOVY, 2002, p.106-110).

Em fins do XIX e primeiras décadas do XX, a configuração territorial do Brasil dava mostras de certa diferenciação espaço-regional em comparação à do período colonial. Avanços no povoamento e no desenvolvimento econômico, tanto em regiões setentrionais como meridionais, expunham uma expressiva desarticulação interna e disparidades sensíveis, sobretudo entre a zona costeira e o chamado sertão (mais pobre e atrasado, de povoamento rarefeito). De acordo com Milton Santos (2001, p.36), tal cenário revelava "uma época colonial pré-mecânica", vinculada a uma estrutura geoeconômica fragmentada, ainda que se verificassem inversões no desenvolvimento dos transportes e comunicações, a exemplo da ampliação da rede telegráfica.

Dois acontecimentos decisivos explicam estas diferenciações regionais: de um lado, o deslocamento do pólo dinâmico da economia colonial do nordeste para o centro-sul, consubstanciado pela decadência da economia açucareira e o desenvolvimento da mineração; de outro, e ligado a este, a mudança da capital (poder central) de Salvador para o Rio de Janeiro, em 1763. Eles representaram prospectivamente um "deslocamento do centro da vida nacional", que não foi, no entanto, "nem rápido nem drástico" (IANNI, 1996, p.37).

Concorreu, de forma decisiva, a expansão da economia mineradora, na medida em que a mineração representou um forte impulso ao povoamento do interior, impulsionando a criação de núcleos urbanos e, desse modo, dinamizando o desenvolvimento regional. A mineração desenvolveu-se de forma bastante imbricada à vida urbana, sendo a mina o núcleo funcional destas cidades (COSTA, 1988; SINGER, 1968). O povoamento que ela induziu mostrou-se de base predominantemente urbana e complementarmente agrária, demandando gêneros importantes (alimentos, animais de tração, etc.) que, em parte, provinham de outros pontos de Minas, mas também de outras regiões da colônia, como de São Paulo, Rio de Janeiro, sertão nordestino, estâncias do sul, etc. Assim, ao estabelecer fluxos de mercadorias, a mineração induziu a formação de vias de comunicação para São 
Paulo e Rio de Janeiro, principalmente, grafando, sob uma disposição fragmentária, as origens do que seria a futura região sudeste (COSTA, 1988, p.32).

Mesmo com a proclamação da sua independência política em 1822, o país permaneceria até os anos 1930 como uma "colônia econômica", mantendo-se inteiramente dependente do mercado externo.

O cenário socioespacial pós-independência manter-se-ia essencialmente colonial, como atestam a presença do escravismo, do latifúndio, da concentração extrema das riquezas e da discriminação política em relação aos não-proprietários. $\mathrm{E}$ mesmo com alguns avanços em curso, como o fim do regime escravista, a proclamação da República em 1.889, o avanço da cafeicultura e o início da industrialização, o Estado brasileiro, ainda assim, tornar-se-ia ainda mais centralizado, frustrando as expectativas populares e contradizendo, na prática, o sentido federativo.

Durante a Primeira República (1889-1930) o território adquiriu um novo significado, tornando-se um instrumento fundamental à legitimação do Estado. Este passou a contar com o suporte de atividades diplomáticas e militares, adotando crescentemente, como se viu, posições mais pragmáticas. Ampliam-se os domínios territoriais nos setores setentrionais do país, com a incorporação do Acre em 1903, que até então pertencia à Bolívia.

O colapso da ordem econômica internacional de 1929 impactou duramente a economia brasileira, expondo suas fragilidades, dentre elas a forte dependência em relação ao setor agrário-exportador. Ampliavam-se as divergências entre os latifundiários, os interesses dos cafeicultores e o poder central. A sucessão de crises políticas e seus efeitos desastrosos precipitam a Revolução de 1930, sob o comando de Getúlio Vargas e seu grupo. Eles responderão pela imposição golpista de um regime político explicitamente autoritário e centralizador.

\section{MODERNIZAÇÃO DESENVOLVIMENTISMO: DESDOBRAMENTOS SÓCIO-TERRITORIAIS \\ CONSERVADORA IMPLICAÇÕES}

Seguramente a Revolução de 30 representou um marco na formação territorial brasileira. Ela recolocou em cena os dilemas da questão nacional e a necessidade de seu enfrentamento, haja vista as pesadas heranças do passado colonial, tais como do escravismo, coronelismo, autoritarismo, clientelismo, entre outras (IANNI, 1996, p.33). Ela assinalou a ascensão ao poder de Estado de uma burguesia em desenvolvimento e o fim do sistema oligárquico, embora não das oligarquias. Segundo José de Souza Martins (2011), ela buscou "republicanizar a República", alvejando o mandonismo dos chefes políticos locais e regionais, acarretando-Ihes certo "rebaixamento político", mas não propriamente uma "anulação" destes poderes. Isso porque, com o fim do governo Vargas e da subseqüente "restauração da democracia", criaram-se condições a "certa liberdade política", permitindo, assim, "o retorno ao poder dos representantes dos interesses oligárquicos e rurais, mantidos sob controle durante a ditadura" (MARTINS, 2011, p.116).

A criação do Estado Novo (1937-45) representou uma mudança importante na orientação da economia, conferindo primazia às atividades urbano-industriais em relação às agrárias. O que desencadeou uma nova divisão regional do trabalho, centralizada hegemonicamente pelo Sudeste. Por essa via, suplantavam-se as 
regras que mantinham a economia inclinada a agro-exportação, ao mesmo tempo em que se criavam condições institucionais ao desenvolvimento do mercado interno, alçado como o novo eixo da acumulação de capital no país (OLIVEIRA, 2003).

Pela primeira vez estabeleceu-se a formação de "um regime nacional completo e estável de acumulação", marcado pela "dominância do estado-nação enquanto ator central", propiciando, assim, "um regime nacional de acumulação", extensivamente a uma endogeneização da dinâmica econômica, com maior ênfase do fator político (NOVY, 2002, p.114).

Assimetrias entre o retraído setor de bens de consumo e o de bens de produção, em expansão, insuflavam crises que acabavam por conduzir à dinamização do segmento de bens de consumo. Isso implicou em mudanças no padrão de consumo da força de trabalho, favorecidas pelo avanço de migrações rural-urbanas e o crescimento da taxa de população urbana.

Põe-se em curso um "regime intensivo de acumulação", orientado a "uma transformação da esfera da reprodução, dos hábitos de consumo e dos estilos de vida" (NOVY, 2002, p.114-115). Tendo se devotado às classes médias e altas, a política estatal de "desenvolvimento" no Brasil voltou-se, basicamente, à satisfação de altos níveis de consumo de uma pequena minoria da população, o que agravou as desigualdades sociais e elevou o custo social do sistema econômico (FURTADO, 1974; FURTADO, 1998).

A criação de uma massa crítica de trabalhadores urbanos serviu como base de sustentação política do Estado, sob o qual a concentração urbana desempenhou um papel fundamental no desenvolvimento de um projeto nacionalista de industrialização. Em outros termos, influindo no fortalecimento da nova orientação político-econômica, isto é, o desenvolvimentismo. Este se define como política econômica pautada pela superação do subdesenvolvimento nacional, amparado numa estratégia de acumulação de capital na indústria, no sentido de uma industrialização integral, que conta com decidido suporte do Estado e emprego do planejamento na operacionalização de suas ações (BIELSCHOWSKY, 1996).

O desenvolvimentismo tornar-se-ia hegemônico na segunda metade dos anos 50, com o Plano de Metas (1956-60) do governo Juscelino Kubitschek, mantendo-se até os dias atuais. Porém, sob um novo aspecto a partir do governo Lula, em 2003, mesclando o social e as políticas sociais compensatórias com a ortodoxia econômica, podendo-se falar aqui de um neodesenvovimentismo.

Desde a segunda gestão de Getúlio Vargas (1951-1954) esta estratégia teve no BNDE (criado em 1952, e ainda sem o "S" de Social naquele momento, passando a se chamar, em 1982, BNDES - Banco Nacional de Desenvolvimento Econômico e Social) um ator fundamental na sustentação da industrialização. Posteriormente na dotação de infra-estruturas e logísticas territoriais durante o período da ditadura militar (1964-85), sobretudo nos anos 1970, desdobrando suas ações no governo neoliberal de Fernando Henrique Cardoso (1995-2003), quando fomentou privatizações e a desregulamentação/liberalização econômica. No final dos anos 90 , - Banco estatal teve forte atuação na configuração dos eixos nacionais de integração e desenvolvimento, o que demandou substanciais investimentos em infraestruturas regionais. Isso favoreceu ao desenvolvimento de uma nova burguesia no país (OLIVEIRA, 2009 apud ZIBECHI, 2012, p.158).

O processo de modernização deflagrado pelo Estado a partir de 1930 constituiu-se no "eixo básico de formação do Brasil moderno", cuja construção foi erigida como "a meta de todos os governos a partir de Vargas" (MORAES, 1997, p.17). Mais especificamente, a modernização pode ser compreendida como um 
"processo de assimilação progressiva da técnica na vida social" (MORAES, 2005, p.96).

No Brasil ela se realizou como uma modernização marcadamente conservadora, pois pactuada entre o Estado, segmentos hegemônicos da economia e setores organizados da sociedade (como sindicatos). Ela marcou profundamente os rumos do desenvolvimento do país, colocando o objetivo nacional acima dos interesses de classe, ideologicamente apoiada numa espécie de concepção metafísico-romântica em torno de uma suposta identidade nacional, que tomava as diferenças sociais como integradas ou pertencentes a uma única cultura homogênea. Modernizar tornava-se, assim, um imperativo, a palavra de ordem do estatismo populista que então se inaugurava.

Sendo o Estado o agente central de difusão de inovações no território (traço marcante, aliás, de países de capitalismo tardio), as quais eram encetadas através do planejamento, pode-se falar da ocorrência de uma efetiva politização da economia. Sob este aspecto ele se consubstanciou num "Estado estruturante", orientado ao desenvolvimento industrial e material do país, lançando mão de políticas setoriais de industrialização e institucionalização da organização dos mercados de trabalho (CANO, 1993, p.18).

O planejamento se impunha como uma espécie de imperativo, um dispositivo político-instrumental crucial à consecução da modernização, em que pese o cenário de desordem e grandes restrições sócio-territoriais decorrentes da crise internacional de 1929, marcado pela debilidade da estrutura econômica e do próprio empresariado nacionais. O emprego deste instrumento perduraria mesmo com o fim do regime orquestrado por Vargas, mantendo-se a consciência de que caberia ao Estado orientar o processo econômico, de modo a imprimir-lhe maior racionalidade e condições mais efetivas de expansão (BIELSCHOWSKY, 1996, p.251).

Vale lembrar que o período entre 1930-40 expunha tendências que já se insinuavam em países do núcleo do capitalismo, mais especificamente quanto à forma de relacionamento entre Estado e economia, tendências precipitadas pela crise de 29. Reitere-se, apenas, que tal vinculação entre Estado e capitalismo está na origem da formação desse sistema sócio-econômico, mostrando-se mais estreita e expansiva em determinados estados do que em outros (FIORI, 2001, p.163), ganhando relevo certos países da chamada "semiperiferia", como o Brasil.

Operando "como a pré-ideação da intervenção deliberada sobre os diferentes lugares", o "plano" consubstanciava-se como "a proposta de distribuição das inovações no espaço nacional" (MORAES, 1997, p.18). Considerando-se a existência de grandes restrições econômico-territoriais ao desenvolvimento da acumulação no país, com as formas do capital controladas por burguesias regionais (OLIVEIRA, 1989, p.3), sob os influxos de uma fragmentária realização da economia, dificilmente o novo padrão de acumulação poderia ter sido alcançado sem intervenção estatal. É praticamente inconcebível que ele pudesse brotar espontaneamente da interação das forças de mercado, pois impunha demandas por regulações políticas mais complexas, que seriam mais adequadamente conduzidas e executadas pelo Estado.

Entre o começo do século XX e as décadas de 1940-50 via-se no território a "transição" entre o "período anterior" (precedente à unificação do território e do mercado, que perdurou até a Segunda Guerra Mundial) e o início do processo da sua "verdadeira" integração. Esta, grosso modo, seria alcançada a partir de meados dos anos 50 até os anos 70, sob o dinamismo da indústria e da construção nacional. O território já dava mostras de uma rede brasileira de cidades, hierarquizada ao 
plano nacional, adrede à "formação de um esboço de mercado territorial localizado no Centro-Sul" (SANTOS, 2001, p.37).

Estabeleciam-se as bases de uma futura "região concentrada" no país, polarizada por São Paulo (fulcro da concentração do capital privado), com o Sudeste impulsionando uma rede localizada de ferrovias, propiciando usos mais dinâmicos do território, com intercâmbios amparados numa maior divisão territorial do trabalho (SANTOS, 2001, p.266).

Isso representou "um momento preliminar da integração territorial, dado pela fusão regional do Sudeste e do Sul" (SANTOS, 2001, p.42-43). Intensificavam-se sinergias dentro da região concentrada, que destoava sensivelmente das demais regiões, que não cresciam na mesma proporção, expondo densidades estruturais diferenciadas. Seu dinamismo não era alimentado apenas por sua grande capacidade empresarial industrial, mas também por excedentes gerados no Nordeste, pondo em relevo uma função estrutural que as periferias desempenharam na modernização desigual. A efetiva integração do território nacional a partir dos anos 60-70 avançava com a propagação de um "meio técnico científico informacional", conferindo à urbanização um papel estratégico quanto a uma maior inserção do país na economia-mundo.

Lembremos ainda, que com a criação do IBGE em 1942, órgão voltado à administração das questões territoriais e ao suporte de políticas setoriais de desenvolvimento, forjou-se a "unidade territorial pelo centro" (COSTA, 1988).

Em 1943 é criada a Fundação Brasil Central (FBC), instituição vinculada diretamente à presidência da República, com sede na capital federal. A FBC conduziu trabalhos importantes nos estados de Goiás e Mato Grosso, dentre os quais projetos de colonização agrícola, abertura de vias de penetração e frentes pioneiras, ações de povoamento em áreas de fronteira e numerosos estudos técnicos em prospecção mineral, além de serviços de exploração madeireira, sobretudo na região do médio Tocantins e baixo Araguaia, no Pará, em terras atravessadas pela Estrada de Ferro Tocantins. Além disso, construiu a cidade de Aragarças, às margens do Rio Araguaia, nas imediações da Serra do Roncador, no Mato Grosso, onde se instalou a mais importante base de atuação da FBC. Sucederam outras cidades, como Xavantina, servindo de base de apoio a penetrações pela rota Araguaia-Xingu, além de Cachimbo e Jacareacanga, no Pará (MACIEL, 2011).

A partir de meados dos anos 50, afirmava-se uma divisão territorial do trabalho disposta, grosso modo, em grandes complexos regionais diferenciados e contrastantes, quais sejam: a área core e sua periferia integrada, as periferias deprimidas e a fronteira de recursos (BECKER; EGLER, 1994), que evidenciavam distintos momentos históricos da formação territorial do Brasil. Suas estruturas produtivas expunham não apenas diferenciações nas suas bases técnicas e funcionais, como também assimetrias na composição do trabalho, tais como de crescimento de atividades industriais secundárias e terciárias, substituição de atividades artesanais por fabris e criação de novos tipos de serviços. Tais disparidades refletiam a forma e a natureza com que se davam as ligações das demais regiões com a "região líder" (OLIVEIRA, 1989).

Com o retorno de Vargas ao poder (1951-54), dinamizam-se dois processos importantes deflagrados pelo "Estado estruturante": a industrialização subsidiada e a modernização, especialmente no que afeta ao "aparelho econômico" do Estado, o que contou com aportes robustos na dotação de infra-estrutura, energia e transportes. Com isso, estabeleceu-se um padrão de acumulação calcado numa 
prévia expansão do setor industrial de bens de produção. A despeito desta expansão não ter se concretizado totalmente, entabulou condições técnicas e econômicas importantes que alavancariam o grande surto de industrialização e crescimento econômico acelerado no Governo Juscelino Kubitschek (1956-60), com o empreendimento de seu Plano de Metas.

Sua execução respondeu pela alteração de praticamente toda a estrutura econômica do país em apenas cinco anos, conferindo uma estratificação mais avançada e diversificada à economia, com a ampliação de inversões em tempo curto em face de demandas infra-estruturais da produção. Seus pressupostos reafirmavam uma definição nacional-desenvolvimentista de política econômica, mas não de nacionalismo, sintetizando uma política econômica que articulava o Estado, a empresa privada nacional e o capital estrangeiro na promoção do desenvolvimento, com ênfase na industrialização, o que ficou conhecido como o "modelo do tripé" ou "tríplice aliança". "Sob esse aspecto, o governo JK prenunciou os rumos da política econômica realizada, em outro contexto, pelos governos militares após 1964" (FAUSTO, 1995, p.427).

A política de industrialização mostrou-se bastante favorável ao capital monopolista privado, suscitando uma enorme ofensiva de capitais estrangeiros multinacionais, sob um capitalismo politicamente orientado. Enquanto uma "resposta capitalista - tolerada pelos liberais - ao projeto socialista para os países subdesenvolvidos" (FIORI, 2001, p.152), seu pragmatismo operacional aglutinou praticamente a maioria dos segmentos dominantes e suas elites, mais concentrada em São Paulo, em torno do complexo metal-mecânico, nucleado pela indústria automobilística, desde a origem associada ao capital estrangeiro. No entanto, outras frações de menor expressão, mas não menos importantes, integraram a "coalizão desenvolvimentista", tornando o desenvolvimento econômico não apenas intensivo como geograficamente concentrado, fazendo expandir também, e de forma permanente, a fronteira agro-mineral e a fronteira urbana (FIORI, 2001, p.152-153).

Este novo modelo representou um ponto de inflexão, centralizando a capacidade do Estado no incremento de setores inteiros da economia, com grande suporte do BNDE e do Conselho Nacional de Desenvolvimento da Presidência, com ênfase nas grandes obras de infraestrutura e na indústria de base (ZIBECHI, 2012, p.85).

O Plano de Metas representou uma ruptura com a orientação anterior, uma vez que o setor industrial se redefiniria pela priorização que deu ao setor de bens duráveis. Adotaram-se novos padrões financeiros à internacionalização da economia por meio de investimentos diretos, sob estímulo do Estado, visando à superação da crise da balança de pagamentos e a consecução do modelo de desenvolvimento associado. (BECKER; EGLER, 1994, p.82-83). O modelo acarretou outras implicações, como o aumento da concentração de capitais e de renda, impulso inflacionário (por emissão monetária para custeio de obras, dentre as quais a construção de Brasília), endividamento externo e recrudescimento do poder burocrático do Estado, elementos basilares da crise política que se instaurou no governo Jânio Quadros (eleito em 1960), levando à sua renúncia.

No que afeta mais diretamente ao território, dois aspectos do Plano podem ser destacados: o desenvolvimento do setor de transportes e a construção de Brasília.

O primeiro deu ênfase às rodovias, principalmente as de escala nacional, haja vista sua importância na integração física e inter-regional do território como um todo, buscando-se fazer a articulação dos sistemas federal/estadual/municipal. A 
construção dessa malha integrada conferiu um novo desenho espacial às relações inter-regionais, promovendo uma maior e mais ampla mobilidade de capitais e de pessoas, como ficou demonstrado, por exemplo, com os sucessivos fluxos migratórios de regiões deprimidas para aquelas mais dinâmicas. Nesse sentido, a ampliação do sistema viário foi imprescindível à interligação de áreas produtoras de matérias-primas/centros industriais/pontos e mercados internos de consumo, potencializando a articulação inter-regional e, por conseguinte, incrementando o desenvolvimento do mercado interno e das economias urbano-regionais, sobretudo o Centro-Sul (COSTA, 1988).

A consolidação da indústria automobilística e do rodoviarismo no Brasil proporcionada pelo Plano de Metas fixariam condicionantes decisivos na produção estatista do território. Desencadeou-se uma efetiva reestruturação da economia, impulsionando uma urbanização tendencialmente expansiva (marcadamente dispersa, com o avanço do binômio industrialização/urbanização) e, ao mesmo tempo, concentracionista (dada por uma grande articulação de frações hegemônicas do capital, nacional e estrangeiro, redimensionando o desenvolvimento regional desigual, com maior destaque ao sudeste-sul).

Lembremos que o desenvolvimentismo no Brasil seguiu as linhas mestras da escola estruturalista, enfatizando o centralismo administrativo e o crescimento através da polarização econômica espacial (SCHMIDT, 1983, p.124); daí ele ter favorecido estrategicamente a urbanização, posto que esta fornecesse as bases à industrialização. Não por acaso se seguiram as chamadas políticas de desenvolvimento urbano no país, tendo à frente o $\mathrm{BNH}$. A capacitação da cidade em infra-estruturas técnicas potencializa, assim, a reprodução ampliada do capital, com São Paulo protagonizando e monopolizando a maior parte dos recursos ao desenvolvimento urbano-industrial.

A construção de Brasília, por sua vez, explicitou em seus pressupostos uma estratégia geopolítica consoante às mudanças territoriais pretendidas. Sua implantação no Planalto Central operaria como uma base avançada à integração norte/oeste, conectando essas regiões ao centro-sul, base do núcleo dinâmico do capitalismo no país. A implantação progressiva de uma "ossatura de circulação" (ampliada e constituída, sobretudo, a partir dos anos 70, com o PIN - Programa de Integração Nacional), tendo Brasília como pólo de articulação, explicitaria tais objetivos, produzindo um efeito indutor ao povoamento e desenvolvimento da hinterlândia do território. Assim, a nova capital consolidou a afirmação do Estado sobre a totalidade do território, "imprescindível para a expansão do consumo do que era produzido internamente"; construção esta que "teria sido impossível se a indústria já não se houvesse desenvolvido em São Paulo" (SANTOS, 2001, p.45-46).

Embora o Plano de Metas não tenha sido pensado como um plano para o território, mas mais propriamente como um plano à expansão do capitalismo no país em sua fase industrial monopolista, suas implicações socioespaciais foram bastante significativas. Elas envolveram um expressivo desenvolvimento das relações de produção e do conjunto da estrutura social, com primazia nos centros urbanos e industriais mais relevantes do país. A estrutura de classes se desenvolveu e a cidade foi alçada a uma condição de hegemonia no universo cultural, com o "poder político" passando, "em maior escala, às mãos da burguesia industrial" (IANNI, 1991, p.117).

O governo JK e o Plano de Metas representaram, pois, um ajuste total "entre as ideologias geográficas e as políticas territoriais do Estado" objetivando-se em "agressivas políticas territoriais" sem precedentes na história do país, em termos de 
sua produção espacial (MORAES, 2005, p.99). Ele afirmou uma nova divisão interregional do trabalho, acolitada pela materialização de bases logísticas à unificação do mercado nacional. As regiões tornavam-se efetivamente instrumentalizadas pelo planejamento estatal, com o planejamento regional despontando "como instrumento primordial de modernização do país" (MORAES, 2005, p.99).

Punha-se em curso o progressivo esfacelamento de uma estrutura espacial regionalmente compartimentada, promovendo, a partir dos anos 60 , a transição do domínio de uma articulação marcadamente comercial para uma de integração produtiva. Desse modo, a antiga estrutura foi sendo substituída por uma conformação de tipo centro-periferia, com o desenvolvimento de um mercado nacional e de reorganização territorial da economia. O Sudeste concentrava a absorção de indústrias de bens duráveis e de capital - com São Paulo, reitera-se, protagonizando os maiores níveis de produtividade e excedentes econômicos -, paralelamente a deslocamentos de unidades de produção para espaços periféricos através da política de incentivos fiscais. Estas deram suporte aos ritmos de crescimento da indústria, o que contou, em larga medida, com a exploração e depreciação da força de trabalho, sobretudo migrante.

O processo de integração do território avançava, porém realizando-se de forma desigual e seletiva, plasmando diferenciações espaciais por ramos e/ou setores da produção nacional, encetando processos desintegradores e díspares internamente a cada região (CARLEIAL, 1993, p.36).

O período da ditadura militar (1964-85) reafirmou ainda mais a centralização e o autoritarismo do poder do Estado na condução da modernização. A identificação do Brasil com o seu território se atualizava com a adoção da Doutrina de Segurança Nacional, tornando a modernização algo tão somente identificada com os seus aparatos infra-estruturais. Daí poder-se dizer que o regime militar conferiu ao território um valor estratégico, em detrimento de seu conteúdo social.

Embora o golpe militar tenha assinalado mudanças importantes no âmbito do planejamento econômico e regional, não se produziram quaisquer rupturas com a modernização centralizadora e autoritária inaugurada com o Estado Novo. Esta não apenas se manteve como se intensificou durante o regime militar.

Nesse contexto, o planejamento estatal entabulou ações de grande envergadura no território, podendo-se destacar a ampliação da integração nacional e o crescimento do mercado interno, favorecendo a expansão das fronteiras agrominerais na Amazônia e no Centro-Oeste, bem como a implantação dos pólos de desenvolvimento regional. O planejamento governamental, adrede ao engajamento do poder público nas atividades produtivas, respondia, portanto, pela dinamização e reprodução ampliada do capital (IANNI, 1996, p.109) no território nacional, condição pela qual o Estado impunha-lhe maior controle e dominação.

Tal recobrimento geopolítico proporcionou certa homogeneização no âmbito do consumo, contrastando com o agravamento das disparidades socioespaciais, bastante condicionadas pelas ações marcadamente seletivas do planejamento, que privilegiava espaços mais consolidados e dotados de maior dinamismo; traço, aliás, que lhe é conspícuo e reincidente, mantendo-se, até os dias de hoje, uma orientação à reprodução de desigualdades espaciais.

Desse modo, a modernização conservadora operava sob uma efetiva assincronia entre a esfera econômica e a social, com explícita prevalência da primeira. Tal desencontro entre a economia e a sociedade talvez pudesse mesmo ter sido considerado como "um dos segredos da prosperidade dos negócios", posto que as "expansões do capital beneficiam-se das condições adversas sob as quais os 
trabalhadores são obrigados a produzir, no campo e na cidade" (IANNI, 1996, p.112). Corrobora, a propósito, o fato emblemático de a economia brasileira ter se tornado, no início dos anos 1970 (na última fase do ufanismo brasileiro do "Brasil potência"), a oitava economia do mundo, porém, ostentando, contraditoriamente, profundas assimetrias na distribuição da riqueza e na organização do território; o que, guardadas as devidas proporções, prevalece até os nossos dias.

A sociedade pouco se modernizou, pesando para isso heranças oligárquicas e patrimoniais, interesses dominantes colados em diretrizes governamentais e injunções de interesse sobre movimentos sociais, organizações sindicais, partidos políticos e outros espaços de práticas sociais, políticas e culturais (IANNI, 1996, p.111).

Veja-se, por exemplo, que o Nordeste, mesmo com a criação da SUDENE em 1959, apresentava um desenvolvimento industrial que não fora suficiente para absorver os enormes excedentes de força de trabalho da região, com altas taxas de desemprego e subemprego. Isso, aliado ao seu problema histórico de concentração fundiária, fez precipitar grandes fluxos de emigração, sobretudo para o Sudeste e a Amazônia. Ademais, seu parque industrial concentrava-se em Recife, Fortaleza e Salvador, constituído basicamente por indústrias de capital intensivo, com fraca capacidade de gerar empregos.

Embora as desigualdades sociais da região tenham diminuído nas últimas décadas, acompanhadas de mudanças importantes em sua composição produtiva (incremento da produção de bens intermediários, maior diversificação da agropecuária, formação de importantes pólos de desenvolvimento agroindustrial e industrial), o Nordeste, mesmo assim, segue mantendo a "questão regional". São ainda perceptíveis a presença de enclaves e significativas disparidades espaciais, que contrastam com redefinições sub-regionais mais diversificadas e dinâmicas (ARAÚJO, 1997), expondo uma cadeia produtiva mais segmentada, complexa e heterogênea ao longo das últimas décadas.

A Amazônia, por sua vez, só passou a contar com ações governamentais mais abrangentes a partir de 1942, com a criação do Banco de Crédito da Borracha, quando sua população concentrava-se em poucos núcleos urbanos, evidenciando a descontinuidade e a rarefação do seu povoamento. A SPVEA (Superintendência do Plano de Valorização Econômica da Amazônia), criada em 1953, é transformada, em 1966, na SUDAM (Superintendência do Desenvolvimento da Amazônia), sob o governo do general Castelo Branco. Cria-se a Amazônia Legal para fins de ação governamental, com financiamentos e incentivos a projetos agropecuários na faixa de transição entre o cerrado, a mata de terra firme e a floresta semi-úmida. Operações estas que constituíram um verdadeiro "escândalo de malversação de dinheiro público", com a maior parte dos recursos desviada ficando conhecida como o "golpe dos incentivos fiscais". Nesses espaços implantaram-se grandes empresas de exploração madeireira para exportação, madeiras de lei como mogno, cerejeira, jacarandá, entre outras, respondendo, ao lado da atuação de grandes pecuaristas, por expressivas devastações e degradação ambiental, com maior peso à segunda (OLIVEIRA, 1987, p.11-12).

Após o golpe de 1964, a ocupação da fronteira amazônica se tornou uma "prioridade máxima". Amparada na Doutrina de Segurança Nacional, ela passou a ocupar uma "posição-chave frente às prioridades econômicas e geopolíticas de ordem interna e externa" (BECKER, 1990, p.12).

Considerando que sua ocupação tenha se dado de forma altamente conflituosa e predatória, ela mobilizou formas diversificadas de apropriação da terra, 
ganhando escala e ritmo crescentes a apropriação monopolista privada de seus recursos naturais, modelo que representa uma decisão deliberada de nossas elites. A urbanização desempenhou aqui um papel estratégico na ocupação da grande fronteira, tornando-se um instrumento fundamental à mobilidade e aglutinação da força de trabalho na região. Ela operou como foco de atração de migrantes, base de organização do mercado de trabalho e campo de ação político-ideológica do Estado (BECKER, 1990, p.53-55). Não por acaso o Censo de 2000 apontava para a região uma população de 70\% vivendo em cidades (GONÇALVES, 2001, p.111).

Nas últimas décadas a Amazônia tem experimentado uma maior diversidade e fragmentação regional. Sob a atuação de novos atores, ela expõe a expansão de eixos de integração e desenvolvimento, tendo por base a estabilidade e a abertura econômicas. O que sinaliza tanto à recuperação da capacidade executiva do Estado, como a uma estratégia orientada ao alcance de posições mais competitivas nos mercados internacionais (GONÇALVES, 2001, p.120 e 125). Esses empreendimentos na fronteira aprofundam uma estrutura concentracionista e corporativa no território, mobilizando vultosos aportes de capital financeiro, sob a coordenação do Estado. Esse processo, entre outros aspectos, potencializa conflitos ambientais e acirra discussões em torno da sustentabilidade e dos mecanismos de poder sobre o território.

Feitas essas considerações, acresce destacar que a partir do final dos anos 1960 o Estado encetou grandes planos de desenvolvimento no território, que repercutiram sensivelmente em sua formação. O I PND (governo Médici, 1969-74) e, mais especificamente, o PIN (Programa de Integração Nacional, em 1970), buscaram expandir as fronteiras econômicas (agrícola, industrial, agroindustrial, urbana, de povoamento, de infra-estruturas regionais, etc.), a partir do Centro-Sul, recobrindo o Centro-Oeste, Amazônia e Nordeste, dando impulso às articulações inter-regionais e a unificação do mercado.

Na segunda metade dos anos 70, foi lançado o II PND (1975-79), orientado a uma nova onda se substituição de importações como nova estratégia de acumulação. Com ele, intensificaram-se ações na criação de uma economia nacional desigualmente integrada, destacando-se a criação de pólos de desenvolvimento regional.

Esses planos reiteravam uma explícita instrumentalização do território pelo Estado, representando um momento culminante do planejamento governamental no país, que se mostrou tanto mais extenso e intensivo do que em qualquer outro período.

Inequivocamente, ocorreram nesse período avanços notáveis na produção e na difusão do conhecimento, da informação e da tecnologia, estimulando a formação e o desenvolvimento de redes. Todavia, com a crise de balanço de pagamentos que se instalou no país a partir dos anos 1970 (atingindo seu ápice a partir de 1979, sob os efeitos do segundo choque do petróleo e da crise da dívida em 1982), desencadearam-se turbulências econômicas e político-sociais de monta na fase final do período militar. Com compressões da máquina estatal sobre o capital privado e o recrudescimento das tensões na esfera da reprodução social, impôs-se uma situação no país que se tornou incompatível com a manutenção do regime militar, que entrou em colapso entre 1978-1984 (SANTOS, 1993; GEIGER, 2003).

A crise em curso estabelecia um forte traço estagnacionista, expondo a incapacidade de financiamentos pelo Estado, a retração do ingresso de capitais estrangeiros, a ampliação do endividamento externo, o crescimento vertiginoso da escalada inflacionária, o aumento das desigualdades distributivas, a multiplicação do 
desemprego e a intensificação da ocupação informal. O que promovia uma enorme clivagem na distribuição da renda entre o Centro-Sul e o Norte-Nordeste, agravando as disparidades regionais do trabalho (EGLER, 1995; CARLEIAL, 1993).

Esta crise, que se insere num contexto mais amplo de esgotamento e transformação do padrão fordista de acumulação e de suas ramificações socioespaciais na periferia do sistema-mundo, repercutiu no Brasil através de uma progressiva agroindustrialização de seu território. Expressão esta consoante a uma crescente abertura e extroversão da economia que visava a obtenção de superávits na balança comercial, gerando recursos ao custeio da dívida externa.

Sob o agravamento da crise, o planejamento passaria a se orientar ao âmbito abstrato da nova economia, globalizada e de égide financeira, tornando-se praticamente esvaziado do componente territorial.

Com o novo pacto federativo estabelecido pela Constituição Nacional de 1988, as ações do Estado tornar-se-iam mais pontuais, dispersas e segmentadas, em meio ao cenário recessivo dos anos 80 .

Por outro lado, isso impunha demandas crescentes por maior fluidez no território, de informações, mercadorias, etc. Ou seja, urgiam dotações infraestruturais à retomada do desenvolvimento econômico e regional, o que levou a uma revalorização do planejamento territorial pela União a partir dos anos 90 , sob a nomenclatura de ordenamento territorial.

Esta prática contaria com grandes aportes de investimentos públicos e inversões de capitais privados na economia, na área social, ambiental, de informação e conhecimento, conferindo ao território maior ênfase à logística e à capacitação infra-estrutural, priorizando, como se viu, produções orientadas principalmente ao mercado externo e aos negócios (MELLO, 2006, p.272).

\section{CONSIDERAÇÕES FINAIS}

Com a obrigatoriedade constitucional dos Planos PluriAnuais de Ação (PPAs), que ficaram mais conhecidos como "Avança Brasil", deflagram-se estratégias de construção de "eixos" nacionais de integração e desenvolvimento, em torno de espaços previamente selecionados com vistas à aceleração da produção e do crescimento econômico. Eles abrem, na fronteira econômica, grandes oportunidades ao investimento privado em moldes territorialmente corporativos, sinalizando a uma nova regionalização. Para sua concretização, demandam estratégias indutoras de investimentos.

Multiplicam-se, nesse sentido, formas de organização capitalista da produção aos mercados internacionais, que reeditam uma pauta exportadora primária, acentuando preocupações e impactos socioambientais, comprometimento/desestruturação de culturas tradicionais, continuidade de expropriações, etc., produtos, aliás, dos termos de realização da própria acumulação capitalista no território.

Cumpre observar, entretanto, que essas estratégias não são específicas do Brasil, mas são replicadas em diversas partes da América Latina (SILVEIRA, 2005). Ao submeterem os espaços nacionais mais dinâmicos a uma maior competitividade internacional, promovem desconexões de áreas opacas/deprimidas por insuficiência de condições a essa competição, recrudescendo, assim, a desvalorização do trabalho e as desigualdades. 
No início de 2007, no governo Lula, é lançado o PAC (Programa de Aceleração do Crescimento). Saudado por muitos economistas, o Programa se propôs à criação de um conjunto robusto de grandes obras de infra-estrutura visando à alavancagem do crescimento econômico. Ele recobre a construção de hidrelétricas, rodovias (e reformas em parte das já existentes), ferrovias, aeroportos, portos, habitação popular e obras de saneamento.

O PAC retoma, assim, mas sob outra vertente, o Estado investidor dos períodos Vargas e Juscelino Kubitschek, podendo-se dizer, portanto, que o ideário que norteia o Programa é o desenvolvimentista, porém agora com uma clara orientação aos interesses do capital privado-corporativo.

Incidem-lhe críticas contundentes, dentre as quais o de praticamente negligenciar a problemática ambiental (vide, por exemplo, o caso da usina de Belo Monte, com destruição de biomas e expropriação de comunidades indígenas), reafirmando uma lógica estritamente produtivista. O que nos leva a compartilhar da idéia de que as questões ambientais representam uma das contradições fatais do capitalismo.

O PAC, que pouco avançou até o momento, se insere, assim, numa geopolítica internacional de intensas disputas pelo controle de reservas naturais potencialmente de alta rentabilidade, como é o caso da água, com a exploração de rios e tecnologias à produção de hidroeletricidade.

Expondo uma explícita orientação estratégico-empresarial do território (que, aliás, praticamente revoga a participação da sociedade), o modelo econômico em curso mantém grandes projetos de exploração mineral e agrícola, reafirmando-os. Ampliam-se substancialmente o agronegócio e o beneficiamento industrial de recursos primários (minérios, soja, cana-de-açúcar, etc.), sob a perspectiva de um mesmo propósito: inserir cada vez mais o país nos mercados internacionais globalizados.

Trata-se de mercados que estão, cada vez mais, submetidos a redes amplamente diversificadas, estendidas geograficamente, impulsionando a incorporação de lugares e ramos variados da economia aos circuitos de valorização do capital. Desse modo, praticamente todas as atividades produtivas tornam-se subordinadas às dinâmicas do capital nacional e estrangeiro, articulando globalização e localismo ao âmbito dos discursos hegemônicos.

Por contraste, este modelo suscitado maiores contrapartidas em termos de um efetivo desenvolvimento do mercado interno, ainda inconcluso e recoberto por gargalos e enclaves. O mesmo em relação a políticas públicas mais eficazes de distribuição de renda e inclusão social; políticas públicas, aliás, cujo sentido é desafiado pela lógica do mercado e dos negócios, com o Estado se amoldando aos seus interesses. O que impõe desafios e embaraços substanciais ao enfrentamento dos problemas sociais de fundo.

Desse modo, os trabalhadores, sobretudo as frações mais empobrecidas da sociedade, sofrem uma dupla exploração/expropriação. De um lado, resguardam-se os interesses das frações dominantes da sociedade brasileira e, de outro, dos segmentos hegemônicos do capital estrangeiro e transnacional, submetendo esses segmentos a um conjunto de privações, ao par de pressões por resultados no trabalho, subversão de direitos, etc. São traços de uma condição espoliativa que se exacerba.

As estratégias territoriais atuais ao desenvolvimento econômico, muito à frente do pretenso desenvolvimento social proclamado pelo Estado, vêm redefinindo e seccionando o espaço brasileiro. 
Sob o sentido de uma efetiva reestruturação, elas impulsionam, com maior celeridade, formas tecnicamente mais avançadas de organização da cadeia produtiva, sobretudo de informação e comunicação, reduzindo o tempo de circulação.

Tais estratégias, como já observado, encontram no desenvolvimento de uma urbanização turbinada e extensiva, a sua principal expressão e condição, objetivando-se por uma ampla metropolização do território.

$\mathrm{Na}$ medida em que esta urbanização esteja bastante submetida à lógica do capital financeiro (condição hegemônica da economia mundializada), vultosos aportes desse capital são direcionados ao mercado fundiário-imobiliário, imiscuindose à produção do espaço construído. Assim, esse capital fictício e volátil consubstancia-se em formas valorativas à acumulação, em que pese o processo de desvalorização imposto pela crise. Trata-se de "negócios" com o território sob os vetores de novas frentes de valorização, proeminentes na cidade e, sobretudo, no urbano. Negócios crescentes articulados à efetivação do capital financeiro, que traduz um novo momento da urbanização (CARLOS, 2015) e, nesse sentido, atualizando a compreensão da formação territorial.

Portanto, corresponde a esta formação uma intensa especulação do solo urbano e dos construtos imobiliários (vide, por exemplo, a proliferação de condomínios fechados em cidades de portes variados), sob a lógica de um urbanismo de feição empresarial, consoante aos negócios. Sua expansão tem representando, a olhos vistos, 0 acirramento de processos espoliativos, gentrificações e expressões variadas de alienação e estranhamento.

À medida que avança uma ampla privatização corporativa do território e das cidades (SANTOS; SILVEIRA, 2001, p.291), recrudescem-se conformações cada vez mais díspares e difusas, podendo-se divisar enclaves de grandes estruturas empresariais e modernos centros comerciais intercalados por amplas extensões suburbanizadas. Há que se considerar aqui o papel indutor representado pelo automóvel nesse processo, e, por extensão, dos eixos rodoviários, sobretudo os de maior expressão, notadamente no Sudeste. E com a expansão do circuito inferior da economia, o espraiamento da suburbanização torna-se praticamente uma constante, sobretudo nas grandes aglomerações metropolitanas.

Acresce ainda salientar que a crise atual desnuda no país um enorme debilitamento da capacidade de governar do Estado, sinalizando para a exaustão dos arranjos político-institucionais vigentes e o esgotamento da economia. O cenário que se instala é de um efetivo descontrole regulatório por parte do Estado em relação às empresas e seus empreendimentos territoriais.

$\mathrm{Na}$ atuação associada das grandes empresas com atores políticos e elites locais e regionais (que operam notadamente sob a perspectiva do ganho econômico), temos a chave ao controle corporativo privado do território. Sob esta lógica, potencializam-se estratégias diversas de apropriação da riqueza social, com a novidade da multiplicação generalizada de práticas ilícitas, insuflando modalidades de trabalho coercitivo (que são integradas à reprodução ampliada do capital, reeditando situações de uma acumulação primitiva) e a preocupante escalada da cleptocracia no país.

Decorre desta ordem de acontecimentos uma vida cotidiana banalizada, compressiva e tensionada, que avança desacompanhada de maiores expectativas.

Se a economia alçou os negócios ao seu objetivo maior e principal, tornandose praticamente esvaziada de efetivas preocupações em torno dos grandes problemas sociais de nossos tempos, a sua necessária reorientação não virá, 
todavia, sem o concurso de níveis mais elaborados de organização societária e de formação/conscientização. O que vale dizer, de modos politicamente mais estimulantes e influenciadores de se estar e atuar no mundo prático-sensível.

Urge, nessa direção, prodigalizações coletivo-participativas em torno da consecução de novos projetos e experiências territoriais, consoante a efetivas necessidades e desejos sociais, que não se resolverão, entretanto, sob a hegemonia das forças do mercado, mas sim pela práxis cooperativa dos próprios interessados a uma transformação virtuosa dos territórios.

Daí o sentido político dessa urgência.

\section{REFERÊNCIAS BIBLIOGRÁFICAS}

ARAÚJO, T. B. de. (1997) Herança de diferenciação e futuro de fragmentação. Estudos avançados, vol.11, n.29, p.7-36.

BECKER, B. Amazônia. São Paulo: Ática, 1990. 112p.

BECKER, B.; EGLER, C. Brasil: uma nova potência regional na economia mundo. Rio de Janeiro: Bertrand Brasil, 1994. 265p.

BIELSCHOWSKY, R. O pensamento econômico brasileiro: o ciclo ideológico do desenvolvimentismo. $3^{\mathrm{a}}$. edição. Rio de Janeiro: Contraponto, 1996. 480p.

CANO, W. Reflexões sobre o Brasil e a nova (des)ordem internacional. $2^{a}$. edição. Campinas: Editora da UNICAMP; São Paulo, FAPESP, 1993. 184p.

CARLEIAL, L. A questão regional no Brasil contemporâneo. LAVINAS, L. et al. (orgs) Reestruturação do espaço urbano e regional no Brasil. São Paulo, Hucitec/ANPUR, 1993. p.35-58.

CARLOS, A. F. A. Do lugar do negócio à cidade como negócio. CARLOS, A. F. A. et al. (orgs). A cidade como negócio. São Paulo: Contexto, 2015. p.43-63.

COSTA, W. M. da. O Estado e as políticas territoriais no Brasil. São Paulo: Contexto/Edusp, 1988. 83p.

EGLER, C. A questão regional no Brasil. BECKER, B. K et al. (orgs.). Geografia e meio ambiente no Brasil. São Paulo: Hucitec, 1995. p.218-234.

FAUSTO, B. História do Brasil. São Paulo: Edusp/FDE, 1995. 688p.

FIORI, J. L. Brasil no espaço. Petrópolis: Vozes, 2001. 268p.

FURTADO, C. O capitalismo global. Rio de Janeiro: Paz e Terra, 1988. 83p.

FURTADO, C. $\mathbf{O}$ mito do desenvolvimento econômico. $4^{\text {a }}$. edição. Rio de Janeiro:

Paz e Terra, 1974. 117p.

GEIGER, P. P. As formas do espaço brasileiro. Rio de Janeiro: Jorge Zahar Editor, 2003. 86p.

GONÇALVES, C. W. P. Amazônia, Amazônias. São Paulo: Contexto, 2001. 178p.

HARVEY, D. A condição pós-moderna. São Paulo: Edições Loyola, 1992. 349p.

HARVEY, D. O novo imperialismo. São Paulo: Loyola, 2004. 207p.

IANNI, O. A idéia de Brasil moderno. São Paulo: Brasiliense, 1996. 180p.

LENCIONI, S. Metropolização do espaço e a constituição de megarregiões. FERREIRA, A. et al. (orgs) Desafios da metropolização do espaço. Rio de Janeiro: Consequência, 2015. p.35-68.

MACIEL, D. P. Estado e território no Centro-Oeste brasileiro (1943-1967). Fundação Brasil Central (FBC): a instituição e inserção regional no contexto sócio-cultural e econômico nacional. Anais do XXVI Simpósio Nacional de História - ANPUH. São Paulo, julho, 2011, s/p. 
MARTINS, J. S. A política do Brasil: lúmpen e místico. São Paulo: Contexto, 2011. 252p.

MELLO, N. A. Políticas territoriais na Amazônia. São Paulo: Annablume, 2006. 410p.

MORAES, A. C. R. Meio ambiente e ciências humanas. 2a. Edição. São Paulo: Hucitec, 1997. 100p.

MORAES, A. C. R. Território e história no Brasil. $2^{a}$. edição. São Paulo: Annablume, 2005. 154p.

MORAES, A. C. R.; COSTA, W. M. da. Geografia crítica: a valorização do espaço. $2^{a}$. edição. São Paulo: Hucitec, 1987. 196p.

NOVY, A. A des-ordem da periferia: 500 anos de espaço e poder no Brasil. Petrópolis: Vozes, 2002. 423p.

OLIVEIRA, A. U. de. Amazônia: monopólio, expropriação e conflitos. Campinas: Papirus, 1987. 133p.

OLIVEIRA, F. de. Crítica à razão dualista, o ornitorrinco. São Paulo: Boitempo, 2003. 150p.

PIKETTY, T. O capital no século XXI. São Paulo: Intrínseca, 2014. 669p.

SANTOS, M. A urbanização brasileira. São Paulo: Hucitec, 1993.157p.

SANTOS, M. Metamorfoses do espaço habitado. São Paulo: Hucitec, 1988.124p.

SANTOS, M.; SILVEIRA, M. L. O Brasil: território e sociedade no início do século XXI. Rio de Janeiro: Record, 2001. 471p.

SAQUET, M. A. Abordagens e concepções de território. $2^{a}$. edição. São Paulo: Expressão Popular, 2010. 200p.

SCHMIDT, B. V. O Estado e a política urbana no Brasil. Porto Alegre: Editora da Universidade, UFRGS; L\&PM, 1983. 213p.

SILVEIRA, M. L. (org). Continente em chamas: globalização e território na América Latina. Rio de Janeiro: Civilização Brasileira, 2005. 287p.

SINGER, P. Desenvolvimento econômico e evolução urbana. São Paulo: Companhia Editora Nacional/Editora da Universidade de São Paulo, 1968. 377p.

ZIBECHI, R. Brasil potência: entre a integração regional e um novo imperialismo. Rio de Janeiro: Consequência, 2012. 347p. 